\title{
Density dependence and environmental factors affect population stability of an agricultural pest and its specialist parasitoid
}

\author{
William H. Morgan · Elisa Thébault • Colleen L. Seymour · F. J. Frank van Veen
}

Received: 14 March 2016/Accepted: 7 November 2016/Published online: 10 December 2016

(C) The Author(s) 2016. This article is published with open access at Springerlink.com

\begin{abstract}
Host-parasitoid dynamics are intrinsically unstable unless the risk of parasitism is sufficiently heterogeneous among hosts. Spatial aggregation of parasitoids can contribute to this heterogeneity, stabilising host-parasitoid population dynamics and thereby reducing pest outbreaks. We examined the spatial distribution of mango gall fly (Procontarinia matteiana, Kiefer and Cecconi), a non-native pest of South African mango orchards, which is controlled by a single parasitoid (Chrysonotomyia pulcherrima, Kerrich). We assessed whether spatial aggregation of parasitoids is associated with proximity to natural vegetation and/or to host density-dependent and host density-independent factors at three spatial scales. We
\end{abstract}

Handling Editor: Josep Anton Jaques Miret

W. H. Morgan · F. J. F. van Veen ( $₫)$

Centre of Ecology and Conservation, College of Life and Environmental Sciences, University of Exeter, Penryn

Campus, Penryn, Cornwall TR10 9EZ, UK

e-mail: F.J.F.Van-Veen@exeter.ac.uk

C. L. Seymour

South African National Biodiversity Institute, Kirstenbosch Gardens, PVT Bag X7, Claremont 7735, South Africa

E. Thébault Institute of Ecology and Environmental Sciences - Paris, UMR 7618 (UPMC, CNRS, IRD, INRA, UPEC, Paris Diderot), Université Pierre et Marie Curie, 7 Quai St Bernard, 75005 Paris, France found evidence for higher parasitism rates near natural vegetation at the field scale, and inverse host-density dependent and density-independent parasitoid aggregation at both the leaf scale and field scale. Therefore, we conclude that natural vegetation plays a role in promoting stabilising aggregation of parasitoids, possibly through provision of non-host resources (nectar, pollen), in this system.

Keywords Conservation biological control · Integrated pest management - Parasitoid aggregation · Natural enemies · Pest control

\section{Introduction}

In agricultural landscapes, natural vegetation has been associated with improved pest control (Thies and Tscharntke 1999; Thies et al. 2011). In understanding the mechanisms behind this control, much of the focus has been on the role of natural vegetation in encouraging greater abundance and diversity of natural enemies (Bianchi et al. 2006). A less explored idea is the role of natural vegetation in promoting aggregation of parasitoids (but see Thomson and Hoffmann 2013) and stabilising host-parasitoid population dynamics by providing a host "refuge" deeper within the crop (Holt and Hassell 1993). Specialist parasitoids have been shown to exert important long-term suppression of their host species, so the role of 
parasitoids in biocontrol is particularly important (Snyder and Ives 2001, 2003). However, the dynamics of simple host-parasitoid interactions are inherently unstable and prone to diverging oscillations, resulting in extinction of one or both species, and cycles of high host abundance (Hassell 2000). A stable pest population maintained at a low level by a specialist parasitoid may therefore be more desirable for successful biocontrol. Integrated pest management programs that tolerate a level of pest infestation below the economic threshold could help maintain environmental quality and reduce unnecessary management activities and costs (Cameron et al. 2001; El-Wakeil 2010).

Theoretically, host populations will be stabilised if the distribution of searching parasitoids is sufficiently heterogeneous (Hassell et al. 1991). This has been defined through the " $\mathrm{CV}^{2}>1$ rule", where the squared coefficient of the variation $\left(\mathrm{CV}^{2}\right)$ of the distribution of searching parasitoids is $>1$ (Hassell et al. 1990). Any variation in parasitism of hosts between patches reduces searching efficiency as parasitoid density increases, and two important sources of this variation are host density-dependent (HDD) parasitoid aggregation, and host density-independent (HDI) parasitoid aggregation (Hassell et al. 1991; Pacala and Hassell 1991). If heterogeneity is the key to stability, one would expect that in a homogenous agricultural setting simple host-parasitoid interactions would be particularly prone to diverging oscillations. Therefore, heterogeneity of risk to hosts due to aggregation of parasitoids is vital for the persistence of a stable host-parasitoid interaction (Taylor 1993).

The mango gall fly (Procontarinia matteiana, Kiefer and Cecconi; Diptera: Cecidomyiidae) is a recognised pest of mangos (Mangifera indica) across the world, from South Africa, where its impact has been recorded by commercial mango farmers (Louw and Labuschagne 2011), to Pakistan and India where recordings are widespread (Jhala et al. 1987; Mahmood Ur Rehman et al. 2013). Adult females lay their eggs on the underside of young leaves, and the emerging larvae burrow into the leaf tissue where they begin to feed (Augustyn et al. 2013). Heavy infestations can result in deformed leaves that drop prematurely, and even cause die-back of new growth (Grové et al. 2002). Differential susceptibility exists between different cultivars of mango owing to varying degrees of antibiosis that they exhibit (Githure et al. 1998). In the commercial mango-growing region of South Africa, P. matteiana is controlled by one specialised, non-native parasitoid: Chrysonotomyia pulcherrima (Kerrich), which was identified by studying the seasonal occurrence of the gall fly and its natural enemies (Grové et al. 2003, 2004). C. pulcherrima is an ectoparasitoid that was not intentionally released and is not reared in insectaries in South Africa. To our knowledge its provenance is also not known, but it may have arrived with its host in larval form. Generally very little is known about the parasitoids associated with gall-inducing insects (Raman et al. 2009), but $C$. pulcherrima has a phenology that is well-synchronised with that of the gall fly, which is its only host. This synchronicity was determined through rearing the host and its parasitoid over a three year period (Mahmood Ur Rehman et al. 2013).

The interaction between $P$. matteiana and $C$. pulcherrima is an example of a simple host-parasitoid system, so is expected to be unstable and prone to diverging oscillations, resulting in the extinction of one or both species (Hassell 2000). Yet in this instance, the host-parasitoid interaction appears to be stable, with both species being described in South African mango orchards for over 25 years by the South African Mango Growers Association (Botha and Kotzé 1987). Botha and Kotzé (1987) first investigated the galls when it was thought that $P$. matteiana may be a vector for bacterial black spot. It is conceivable that some form of parasitoid aggregation is providing the stability needed for the stable persistence of these two species. South Africa's commercial mango-growing region is characterised by orchards surrounded by large areas of natural "bushveld" vegetation (Granite Lowveld; Mucina and Rutherford 2006), and it may be that natural vegetation provides one source of parasitoid aggregation. While not a source of $C$. pulcherrima, the natural vegetation may provide other benefits such as shade, shelter, and food sources in the form of pollen and nectar (Bianchi et al. 2006). Supplementing diet with sugar resources has been shown to confer improved fitness for parasitoids, resulting in increases to longevity and potential fecundity (Tylianakis et al. 2004; Protasov et al. 2007). In fact, previous studies in South African mango farms of $P$. matteiana and its parasitoid $C$. pulcherrima suggest that rates of parasitism were higher closer to the natural vegetation than in the middle of mango orchards (Henri et al. 2015). A 
beneficial effect of proximate natural vegetation for parasitoids could conceivably result in aggregation at the interface between agricultural and natural habitats, providing a "refuge" for hosts deeper in the crop. This, along with HDD aggregation, HDI aggregation, or both, could provide the heterogeneity of risk required to regulate this host-parasitoid interaction.

Here we report on a field study that aimed to test the hypothesis that even for single, non-native hostspecialist parasitoid interactions, natural vegetation provides an ecosystem service by supporting parasitoids and thus allowing their aggregation, using mango orchards in South Africa as a case study. We characterized the spatial distribution of gall flies and of parasitism rates within mango orchards to test for the relative importance of host density, distance to natural vegetation, and other density-independent factors in constituting heterogeneity of risk to hosts. Uncovering patterns in parasitoid aggregation allowed us to evaluate the importance of proximate natural vegetation to stabilising this interaction, and also highlighted areas of potential further study into parasitoid foraging behaviour.

\section{Methods}

Study site

All work was carried out in the commercial mango farming region in the Limpopo province of South Africa. Surveys were performed on two separate mango farms in the region: Bavaria Estates $\left(24^{\circ} 24^{\prime} 24.94^{\prime \prime} \mathrm{S} \quad 30^{\circ} 53^{\prime} 34.96^{\prime \prime} \mathrm{E}\right)$, and Mohlatsi $\left(24^{\circ} 30^{\prime} 30.27^{\prime \prime} \mathrm{S} 30^{\circ} 49^{\prime} 34.13^{\prime \prime} \mathrm{E}\right)$. Work was carried out between 1 March 2014 and 31 May 2014, coinciding with the summer lifecycle of the gall fly that lasts approximately four months from February onwards (Grové et al. 2003). Surveys were carried out in areas of the farms bordering natural vegetation. Granite Lowveld is part of the southern African savannah biome, characterised by tall Acacia nilotica and Sclerocarya birrea trees and various Combretum and Grewia spp. shrubs. Individual mango orchards are bordered by Casuarina spp. for protection from wind, and generally there was a gap of $\sim 20 \mathrm{~m}$ between the edge of the mango orchard and the natural vegetation.

Two cultivars were chosen for this study because of their reported differential susceptibility to infestation by gall flies: Tommy Atkins, which is a susceptible, true-gall forming cultivar; and Kent, which is a less susceptible, often pseudo-gall forming cultivar (Githure et al. 1998). A total of nine separate fields were used for the surveys, six on Bavaria Estates and three on Mohlatsi. All fields on Mohlatsi were Tommy Atkins, while on Bavaria Estates three fields were Tommy Atkins and three were Kent.

\section{Gall density}

In order to characterise spatially where gall flies are active we assessed the density of galls on individual leaves. Leaves were collected from trees in $20 \times 3 \mathrm{~m}$ transects at $0,10,50,100$ and $200 \mathrm{~m}$ from natural vegetation from the nine mango fields. Two trees were randomly selected at each distance, and from each tree, two leaves were picked from high $(>180 \mathrm{~cm}$ high) and two from low in the tree $(<180 \mathrm{~cm}$ high). This followed protocol from previous work looking at gall fly abundance and rates of parasitism (Henri et al. 2015). Leaves were placed in the freezer for at least $24 \mathrm{~h}$, in order to kill any gall flies or parasitoids, after which time the number of galls on each leaf was counted. For each tree the total number of galls for high leaves and low leaves was calculated. The size of leaves was not recorded due to the stage in leaf development that ovipositing occurs. Gall flies oviposit on flush leaves at the spike stage, so eventual leaf size is of little relevance (Augustyn et al. 2013).

Data exploration revealed that gall density data were zero inflated, and as gall flies oviposit during the spike stage of leaf development, leaves may have zero galls on them for one of two reasons: (i) gall flies were present but did not lay eggs on the leaf, and (ii) the timing of the leaf flush did not coincide with an emergence of gall flies so no gall flies were present to lay eggs. We were unable to distinguish between these two types of zeros, and so used a zero inflated mixture model with a single zero-inflation parameter (Zuur et al. 2009). Therefore, to assess how gall density varied throughout fields, zero inflated generalized linear mixed models (ZIGLMM) (negative binomial error structure with a logit link for the binomial component and a log link for the count component) were used with distance (centred by subtracting the mean), cultivar and position in the tree (two modalities: high and low) included as fixed effects. Farm, field and tree were nested random effects. Models 
containing all of the fixed effects were compared using Akaike's information criterion (AIC) with a second order correction for small sample sizes (AICc) to find the model that best describes the data (Burnham and Anderson 2002). The model with the smallest AICc is considered the best model, and models that differ by AICc $<2$ are considered to fit equally well. We also calculated Akaike weights, which give the probability that a model is the best of a set of candidate models (Wagenmakers and Farrell 2004). Statistical analysis was carried out in software package $\mathrm{R}$, version 3.0.3 using packages glmmADMB, stats4, bbmle and Mass (Venables and Ripley 2002; Fournier et al. 2012; Bolker and R Core Team 2014).

\section{Parasitism}

To assess the rate of parasitism, leaves were collected in the same manner as for assessing gall density, though this was done twice in two fields from each farm to increase the sample size. The first collection was carried out between 31 March 2014 and 12 May 2014, and the repeat collections were between 12 May 2014 and 20 May 2014, which overlap with the generation of parasitoids that emerges between February and March. Of the leaves picked that had some mature galls, two were selected at random from each tree. Mature galls were judged to be those which had begun to turn brown due to the plant tissue becoming necrotic and drying out, which is considered a sign that the gall fly or parasitoid is preparing to emerge (Louw and Labuschagne 2011). Five mature galls were randomly selected from each leaf and dissected under a light microscope. The contents of each gall was classified as $P$. matteiana (larvae, pupae or adult), C. pulcherrima (larvae, pupae or adult), or unidentified (empty, immature, vacated or dead). If the contents of all galls were unidentified then another leaf was selected and five more galls were dissected. Identification of contents was carried out using pictures from Augustyn et al. (2013), Louw and Labuschagne (2011) and ecoport (Githure 2014). Proportion parasitism was calculated per leaf. The total number of galls per leaf was also recorded to test for HDD and HDI aggregation of parasitoids.

The null hypothesis states that risk of parasitism of galls will be constant across patches and that the variance in parasitism will be no more than expected from a binomial distribution (van Veen et al. 2002). To assess any deviation from the null model, a generalized linear mixed effects model (GLMM) (binomial error structure with logit link function) for proportion parasitism was created with the log of gall density as a fixed effect, farm and field as nested random effects, and sampling event included as a crossed random effect. Log of gall density was used as this improved model convergence. To test for HDI aggregation, the dispersion factor [the ratio of residual deviance to residual degrees of freedom (df)] can be used to test for a departure from the null hypothesis and is tested for significance using $\chi^{2}$ on the residual deviance at the residual degrees of freedom (van Veen et al. 2002; Hougardy and Mills 2009).

To test for HDD aggregation, the same model was used, but with the addition of a standardized random effect with a normal distribution to account for overdispersion (Browne and Subramanian 2005). Likelihood ratio tests were performed to test the significance of gall density on rate of parasitism and the marginal and conditional $\mathrm{R}^{2}$ were calculated to assess the amount of variance explained by the fixed and random effects (Nakagawa and Schielzeth 2013).

In order to investigate HDD and HDI parasitoid aggregation at spatial scales greater than the leaf, parasitism data were first pooled for each distance within each field (the field scale) and then pooled for each field (the landscape scale). Tests for HDD and HDI aggregation were carried out using the method described above.

To develop an understanding of how parasitism varied throughout fields, generalized linear mixed effects models (GLMM) (binomial error structure and logit link function) were created that again included farm and field as nested random effects, sampling event (first or second) as a crossed random effect, and a standardized random effect with a normal distribution was used to account for overdispersion when required (Browne and Subramanian 2005). For analysis of pattern at the leaf scale, models were built containing all combinations of the fixed effects, $\log$ of gall density, cultivar, height in tree, and the log of distance from natural vegetation $[\log (1+$ distance $)]$. Log of gall density and distance were used to improve model convergence. At the field scale, models were built containing log of gall density, log of distance from natural vegetation and cultivar. Finally, for the landscape scale, models were built containing log of gall density and cultivar. Where relevant, at each scale, we also ran models that included the interaction 
between distance from natural vegetation and gall density. For each spatial scale, models were compared using AICc (Burnham and Anderson 2002). Akaike weights were also calculated, along with the $95 \%$ confidence set of models (Wagenmakers and Farrell 2004). Likelihood ratio tests were then carried out to test the significance of fixed effects. Finally the marginal and conditional $\mathrm{R}^{2}$ were calculated for the best fitting models to assess the amount of variance explained by the fixed and random effects (Nakagawa and Schielzeth 2013). Statistical analyses were performed using the software package R, version 3.0.3, and the packages lmerTest (Kuznetsova et al. 2014), bbmle (Bolker and R Core Team 2014) and boot (Canty and Ripley 2014).

\section{Results}

\section{Gall density}

A total of 356 leaves were measured for gall density and the number of galls per leaf ranged from 0 to 1034 . Model selection based on AICc found that the best fitting model contained the fixed effects of cultivar and height, with gall density higher in the Tommy Atkins cultivar than in the Kent cultivar, and higher for leaves higher up in the tree (AICc $=1756.5$, Akaike weight $=0.46)$. For leaves high in the tree the best model predicts a gall density $( \pm$ SE) of $3.36( \pm 0.72)$ per leaf for the Kent cultivar and $4.66( \pm 0.64)$ for the Tommy Atkins cultivar. For both cultivars, gall density for leaves lower in the tree is predicted to be 0.63 $( \pm 0.26)$ lower. The second best fitting model $(\triangle \mathrm{AICc}=1.9$, Akaike weight $=0.18)$ contained only the effect of height, and the third best fitting model $(\triangle \mathrm{AICc}=2.1$, Akaike weight $=0.16)$ contained the effects of height, cultivar and distance from natural vegetation. All models predicted higher gall densities in Tommy Atkins than Kent cultivars, and higher gall densities high in the tree than low in the tree.

\section{Parasitism}

We dissected 1266 galls, finding gall flies in $18.5 \%$ of galls, and parasitoids in $9.2 \%$. The remainder (72.4\%) were either empty, had been vacated, or the contents were unidentifiable. The proportion of galls containing neither a gall fly or parasitoid was not affected by the cultivar $\left(\chi_{1}^{2}=0.012, P=0.918\right)$, and all pests found within intact galls were identified as $P$. matteiana, and all parasitoids were identified as $C$. pulcherrima.

We found evidence for HDI aggregation at the scale of the leaf (residual deviance $=194.63$, residual $\mathrm{df}=$ 105 , dispersion factor $=1.85, P<0.0001)$ and at the scale of the field (residual deviance $=99.09$, residual df $=52$, dispersion factor $=1.91, P=0.0001)$, but not at the landscape scale (residual deviance $=11.52$, residual $\mathrm{df}=8$, dispersion factor $=1.42, P=0.17$ ). We also found significant inverse HDD aggregation at the leaf scale $\left(\chi_{1}^{2}=5.418, P=0.020\right)$ and field scale $\left(\chi_{1}^{2}=8.009, P=0.005\right)$, but not at the landscape scale $\left(\chi_{1}^{2}=1.253, P=0.263\right)$.

At the scale of the leaf, model selection based on AICc found a range of candidate models that could explain the data. There were 11 models in the $95 \%$ confidence set, suggesting significant model uncertainty. Parameter estimates suggest that proportion parasitism decreases with increasing distance from natural vegetation and greater gall density, and is also less in Tommy Atkins fields and lower down in trees $(<180 \mathrm{~cm})$. Due to this model uncertainty, likelihood ratio tests were carried out, which revealed that only gall density had a significant, negative effect on proportion parasitism $\left(\chi_{1}^{2}=5.418, P=0.020\right.$, Fig. 1$)$. When the effect of gall density was removed from the model, the effects of height in tree and cultivar remained insignificant $(P=0.565$ and $P=0.184$ respectively). The marginal $\mathrm{R}^{2}$, the amount of variation explained by the fixed effect only was low (0.04), suggesting that there are other important sources of variation that we have not accounted for.

At the field scale, the models that best fit the data contained the effects of gall density and distance from natural vegetation, with equal support for a model containing the interaction term as for one with just main effects (AICc $=169.3$ and 169.6 respectively). Again, parameter estimates suggest that proportion parasitism decreases with increasing gall density and distance from natural vegetation (Fig. 2). While the third best model had a $\triangle \mathrm{AICc}$ of only 1.6 and includes only the effect of gall density, at this spatial scale there is stronger support for an effect of distance from natural vegetation. Likelihood ratio tests reveal that both gall density and distance from natural vegetation explain a significant amount of variation in proportion 


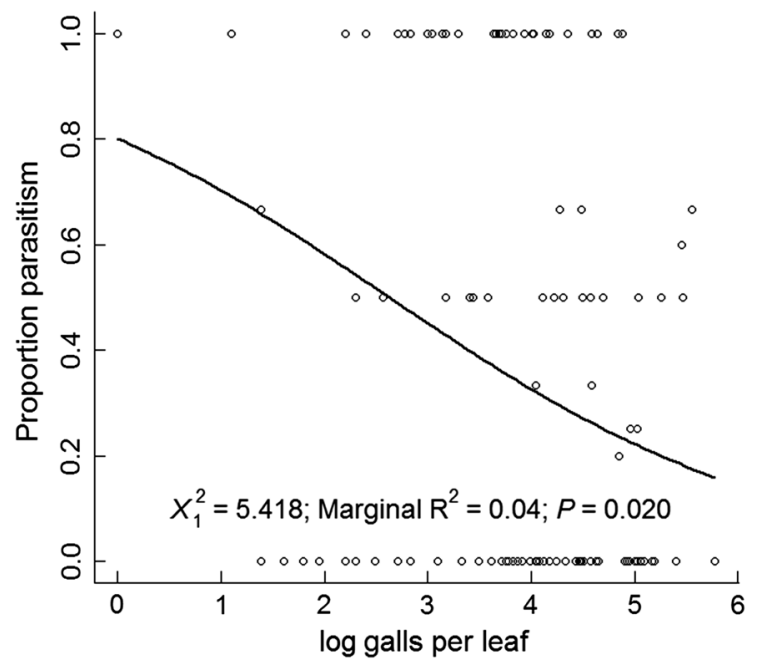

Fig. 1 The relationship between proportion parasitism and number of galls per leaf. Proportion parasitism was calculated at the level of the individual leaf. The line of best fit describes a generalized linear mixed effects model with a binomial error structure that includes the main effect of log of gall density. The marginal $\mathrm{R}^{2}$ is the amount of variance explained by the fixed effects

parasitism $\left(\chi_{1}^{2}=10.02, \quad P=0.002\right.$, Fig. $2 \mathrm{a}$, and $\chi_{1}^{2}=3.884, P=0.049$, Fig. 2a respectively). However, the interaction term was not significant $\left(\chi_{1}^{2}=2.991, P=0.083\right.$, Fig. $\left.2 b\right)$. The model including only main effects had a marginal $\mathrm{R}^{2}$ of 0.108 , and the model with the interaction term had a marginal $\mathrm{R}^{2}$ of 0.150 , suggesting that gall density and natural vegetation explain a greater proportion of the variance at this larger spatial scale.

At the landscape scale, the model that best fit the data was the null model, and models containing fixed effects of gall density or cultivar had $\Delta$ AICc of 4.3 and 4.4 respectively. Similarly, likelihood ratio tests found that gall density and cultivar did not explain a significant amount of the variation in proportion parasitism $(P=0.263$ and $P=0.272$ respectively). It is, however, important to note the direction of the effect of gall density on parasitism rate, which in agreement with the other spatial scales was negative (effect size $=-0.255, \mathrm{SE}=0.230$ ).

\section{Discussion}

Stable pest populations are preferable to those characterised by cycles of outbreak, particularly if damage
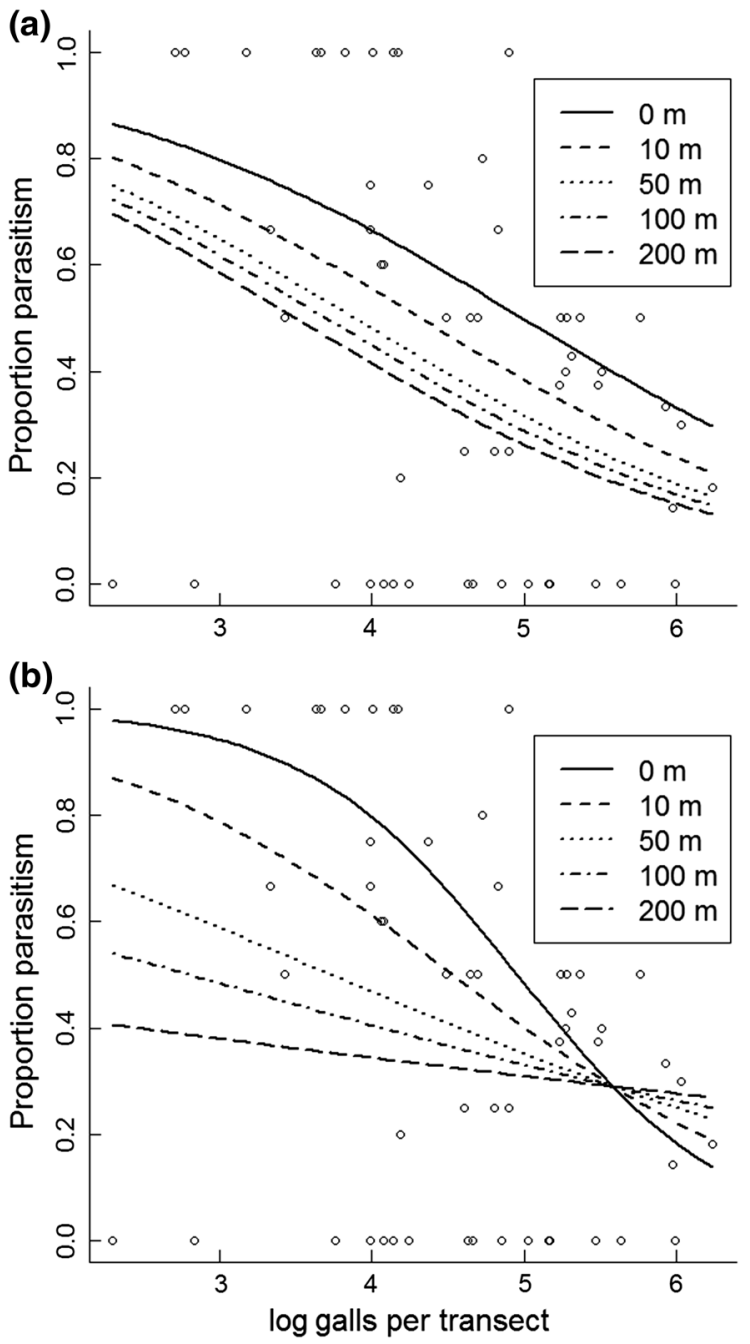

Fig. 2 The relationship between proportion parasitism and gall density at different distances from natural vegetation. Parasitism data were pooled for each distance within each field. a Shows predictions of a generalized linear mixed effects model with a binomial error structure that includes the main effects of log of gall density and $\log (1+$ distance from natural vegetation $)$, and b shows predictions from a model with the same main effects, but including the interaction term between gall density and distance from natural vegetation

caused by that pest is at an acceptable level, below the economic threshold (Cameron et al. 2001; El-Wakeil 2010). By assessing the effect of host density on parasitism rate, we found evidence of both HDD and HDI aggregation of parasitoids at the scale of the leaf and at the scale of the field. At both scales we found inverse HDD aggregation, meaning areas of greater host density have a lower proportion of parasitism. Areas of high host density therefore offer a 
probabilistic refuge for gall flies, which may help maintain a stable host population (Taylor 1993). We also found HDI aggregation; where aggregation of a parasitoid happens independently of host densities, and together with HDD aggregation contributes to population stability (Hassell et al. 1991).

The role of natural vegetation in causing aggregation of parasitoids was the main HDI factor investigated in this study. At the scale of the field, our results provide good evidence that proportion parasitism decreases with distance from natural vegetation, as in a previous study (Henri et al. 2015), suggesting that natural vegetation may play a role in causing aggregation of searching parasitoids. For specialist parasitoids, natural vegetation cannot act as a source of alternative hosts but it can support parasitoids by providing food in the form of pollen and nectar (Tylianakis et al. 2004; Bianchi et al. 2006; Protasov et al. 2007). There is also some evidence for an interaction between gall density and distance from natural vegetation. The interpretation of this interaction is that where host densities are low close to natural vegetation a very high proportion are parasitized, but parasitism rate drops off quickly as host density increases. Where host densities are low further away from natural vegetation, a lower proportion of hosts are parasitized, but the rate of parasitism decreases at a reduced rate as host densities increase.

At the scale of the leaf there was some evidence that proportion parasitism decreases with distance from natural vegetation, although other models that fit the data equally well suggest no effect of distance. One possible explanation for the weaker effect of distance from natural vegetation at this smaller spatial scale is that large variation in host densities between leaves may result in host-density effects masking the effect proximity to natural vegetation has on parasitism rate.

At the landscape scale, where data were pooled for each field, we found no evidence for HDI aggregation. Pooling the data at this scale removes the effect of distance from natural vegetation, as data is pooled across all distances. The fact that no HDI aggregation was found at this scale lends weight to the argument that natural vegetation bordering mango fields plays a role in causing aggregation of parasitoids.

Mango orchards contain weeds that flower prolifically given the water and nutrient availability in mango fields, and these weeds may also provide a source of pollen and nectar to searching parasitoids.
Investigating HDI aggregation of parasitoids in fields that are weed free could reveal an even stronger effect of natural vegetation in causing this stabilising aggregation, unless $C$. pulcherrima is not limited by foraging distance at this spatial scale.

The natural vegetation bordering the mango fields used in this study is highly heterogeneous, with a diversity of species belonging to the Fabaceae, Malvaceae, Combretaceae, and Anacardiaceae amongst the woody species and numerous herbaceous flowering species. This diversity creates patchiness in forage resources for parasitoids, which may play an important role at the landscape scale and mask the effect of aggregation due to host densities. However, at the landscape scale we also found no evidence of HDI aggregation, suggesting that parasitoids are distributed evenly at this spatial scale.

Another explanation for the presence of HDI aggregation may be that parasitoids do not find all infested leaves while foraging. While specialist parasitoids are more effective at searching for hosts than generalists (Wang and Keller 2002), plant structural complexity plays an important role in determining host-finding (Andow and Prokrym 1990). Mango trees have high structural complexity due to their large size and surface area, and this could lead to variation among infested leaves in the probability of discovery by a parasitoid.

Here we have shown evidence of inverse HDD aggregation at the scale of the leaf and at the scale of the field. At the scale of the leaf, this may suggest that at high host densities, parasitoids become egg-limited and parasitism rate slows. This is an example of a type 2 functional response (Ives 1992). Such inverse HDD at small spatial scales has been observed before, where a constant number of parasitoids searching randomly will result in inverse density dependence (Heads and Lawton 1983). While little is known about ovipositing behaviour of $C$. pulcherrima, they are very small parasitoids and as a consequence may carry a limited number of eggs (O’Neill and Skinner 1990). Inverse HDD aggregation has also been observed as a strategy to avoid self-superparasitism in species that have little ability to discriminate between parasitized and unparasitized hosts. Parasitoids leave patches before they are fully exploited, to reduce the risk of allocating additional eggs and time to hosts that have already been parasitized (Rosenheim and Mangel 1994). For a small parasitoid that is potentially egg-limited, avoiding this extra cost is of particular importance. 
At the scale of the field we see the same pattern of reduced parasitism at high host densities, consistent with the suggestion that parasitoids may be egglimited. At this spatial scale, there is a much clearer effect of distance from natural vegetation, with absolute parasitism rate decreasing further into the crop. This suggests there is a reduction in the number of searching parasitoids further into the crop.

We found greater gall density higher in the trees. This is likely due to a preference of gall flies for warm, sunny conditions (Grové et al. 2002). There was no evidence for a height preference in the parasitoids in addition to any HDD effects. We found weak evidence that proportion parasitism is lower in Tommy Atkins orchards than in Kent orchards, but this is likely driven by (inverse) HDD effects as Tommy Atkins orchards showed significantly higher gall density than Kent orchards. This suggests that differences in proportion parasitism between cultivars is a result of different gall densities, and not a preference of the parasitoid for certain cultivars.

During this study we found that a large proportion of galls contained no gall fly or parasitoid. This may suggest gall fly mortality possibly due to plant defences, though we found no difference in proportion of empty galls between cultivars, which might be expected as Tommy Atkins is more susceptible to infestation than the more resistant Kent cultivar. Another explanation may be predators with piercing mouth parts (though we have never observed such predation in this system), or pathogens.

Very little is known about the foraging behaviour of C. pulcherrima. Ives (1995) argued for the need to couple research on foraging behaviour and population dynamics but this is still rarely done. Parasitoid behaviour will influence foraging distances, and foraging distances determine the appropriate spatial scale to study (Hassell et al. 1990). A better understanding of the behaviour of the parasitoid may lead to better understanding of the mechanisms that lead to HDD and HDI aggregation at a range of spatial scales (Schooler et al. 1996). An important further consideration for HDI aggregation in particular is the consequences for pest control services. While HDI aggregation always provides stability, it also results in lower parasitism rates and higher equilibrium host densities (Ives 1992). Ives (1992) notes the trade-off between stability and the successful control of the host population. Knowledge of the underlying mechanisms improves our ability to manipulate the environment to promote the most desirable outcomes.

We were only able to study one generation of host and parasitoid, and it should be noted that there are two distinct lifecycles per year (Botha and Kotzé 1987). Further study of multiple generations could assess temporal changes to the heterogeneity of risk, revealing how HDD and HDI aggregation contribute to population dynamics for different generations.

Here we have presented a simple host-parasitoid interaction involving one non-native host and a single, specialist, non-native parasitoid (Grové et al. 2004). Grové et al. (2004) report that $C$. pulcherrima is the only known parasitoid of $P$. matteiana in South Africa. Formal theory suggests this simple type of system should be unstable with divergent oscillations, leading to pest outbreaks of increasing severity and local extinctions of one or both species (Hassell 2000). Heterogeneity of risk to hosts-through inverse HDD and HDI parasitoid aggregation-is potentially regulating the system and allowing both species to persist without damaging oscillations. Management practices that seek to maintain the stability of the hostparasitoid interaction may well be preferable to those that seek to eradicate the pest entirely. For example, a reduction of within-field weed control may facilitate the action of this parasitoid species and help ensure long-term control of gall flies without the need for extensive pesticide use. A greater understanding of the degree of infestation a plant can support before yield is affected is vital in informing such management practices, and if host densities increase beyond this, alternative measures of control may have to be considered.

Acknowledgements We would like to thank T. Carroll, W. Lammers, C. Moxley and M. Oddie for assistance in the field; Bavaria Estates and Mohlatsi staff for access to farms and information on pest populations. The research was conducted with financial support to the 'NETWORK' project from the European Commission Marie Curie International Research Staff Exchange Scheme (IRSES) (Grant agreement: PIRSESGA-2012-318929), and funding to CLS from the South African Department of Science and Technology (DST/CON0054/2013) and National Research Foundation (Grant 90139). We thank the farm owners and managers who granted access to field sites.

Open Access This article is distributed under the terms of the Creative Commons Attribution 4.0 International License (http:// creativecommons.org/licenses/by/4.0/), which permits unrestricted use, distribution, and reproduction in any medium, provided you give appropriate credit to the original 
author(s) and the source, provide a link to the Creative Commons license, and indicate if changes were made.

\section{References}

Andow D, Prokrym D (1990) Plant structural complexity and host-finding by a parasitoid. Oecologia 82:162-165

Augustyn WA, du Plooy W, Botha BM, van Wilpe E (2013) Infestation of Mangifera indica by the mango gall fly, Procontarinia matteiana, (Kieffer \& Cecconi) (Diptera: Cecidomyiidae). Afr Entomol 21:79-88

Bianchi FJJ, Booij CJH, Tscharntke T (2006) Sustainable pest regulation in agricultural landscapes: a review on landscape composition, biodiversity and natural pest control. Proc Biol Sci 273:1715-1727

Bolker B, R Core Team (2014) bbmle: tools for general maximum likelihood estimation. $\mathrm{R}$ package version 1.0.17. http://CRAN.R-project.org/package=bbmle. Accessed 5 Oct 2016

Botha W, Kotzé JM (1987) Life cycle of the mango gall fly, Procontarinia matteiana. S Afr Mango Grow Assoc Year B 7:19

Browne W, Subramanian S (2005) Variance partitioning in multilevel logistic models that exhibit overdispersion. J R Stat Soc A 168:599-613

Burnham K, Anderson D (2002) Model selection and multimodel inference: a practical information-theoretic approach, 2nd edn. Springer, New York

Cameron PJ, Walker GP, Herman TJ, Wallace AR (2001) Development of economic thresholds and monitoring systems for Helicoverpa armigera (Lepidoptera: Noctuidae) in tomatoes. J Econ Entomol 94:1104-1112

Canty A, Ripley B (2014) boot: Bootstrap R (S-Plus) functions. $\mathrm{R}$ package version 1.3-10. http://CRAN.R-project.org/ package=boot. Accessed 5 Oct 2016

El-Wakeil N (2010) Insect economic levels in relation to crop production. Arch Phytopathol Plant Prot 43:17101744

Fournier D, Skaug H, Ancheta J, Ianelli J, Magnusson A, Maunder MN, Nielson A, Sibert J (2012) AD Model Builder: using automatic differentiation for statistical inference of highly parameterized complex nonlinear models. Optim Methods Softw 27:233-249

Githure CW (2014) Procontarinia matteiana. http://ecoport. org/ep?Arthropod=26297\&entityType $=$ AR $* * * * \&$ entityDis playCategory=full. Accessed $10 \mathrm{Jul} 2014$

Githure CW, Schoeman AS, McGeogh MA (1998) Differential susceptibility of mango cultivars in South Africa to galling by the mango gall fly, Procontarinia matteiana Kieffer \& Cecconi (Diptera: Cecidomyiidae). S Afr Mango Grow Assoc Year B 6:33-40

Grové T, Steyn WP, de Beer MS (2002) Gall fly on mango. S Afr Mango Grow Assoc Year B 22:6-9

Grové T, Steyn WP, de Beer MS (2003) Biologie van galvlieg. S Afr Mango Grow Assoc Year B 23:102-107

Grové T, Steyn WP, de Beer MS (2004) Seisoenvoorkoms van mangogalvlieg. S Afr Mango Grow Assoc Year B $24: 27-28$
Hassell M (2000) The spatial and temporal dynamics of hostparasitoid interactions. Oxford University Press, Oxford

Hassell M, Pacala S, Tingley G (1990) Heterogeneity and the dynamics of host-parasitoid interactions. Philos Trans R Soc Lond B Biol Sci 330:203-220

Hassell M, May R, Pacala S, Chesson P (1991) The persistence of host-parasitoid associations in patchy environments. I. A general criterion. Am Nat 138:568-583

Heads P, Lawton J (1983) Studies on the natural enemy complex of the holly leaf-miner: the effects of scale on the detection of aggregative responses and the implications for biological control. Oikos 40:267-276

Henri DC, Jones O, Tsiattilos A, Thebault E, Seymour CL, van Veen FJF (2015) Natural vegetation benefits synergistic control of the three main insect and pathogen pests of fruit crop in Southern Africa. J Appl Ecol 52:1092-1101

Holt R, Hassell M (1993) Environmental heterogeneity and the stability of host-parasitoid interactions. J Anim Ecol 62:89-100

Hougardy E, Mills N (2009) Factors influencing the abundance of Trioxys pallidus, a successful introduced biological control agent of walnut aphid in California. Biol Control 48:22-29

Ives A (1992) Density-dependent and density-independent parasitoid aggregation in model host-parasitoid systems. Am Nat 140:912-937

Ives A (1995) Spatial heterogeneity and host-parasitoid population dynamics: do we need to study behavior? Oikos 74:366-376

Jhala R, Patel Z, Shah A (1987) Studies on the relative occurrence of leaf gall midge (Procontarinia matteiana Kieffer and Cecconi) on different varieties of mango in south Gujarat, India. Trop Pest Manag 33:277-279

Kuznetsova A, Brockhoff PB, Christensen RHB (2014) lmerTest: tests in linear mixed effects models. R package version 2.0-20. http://CRAN.R-project.org/package= lmerTest. Accessed 5 Oct 2016

Louw E, Labuschagne C (2011) A photo guide to the identification of mango growth stages, pests and diseases. Bavaria Fruit Estate, Syngenta South Africa and Westfalia Fruit, pp 85-90

Mahmood Ur Rehman H, Mahmood R, Razaq M (2013) Phenology, distribution, biology and population trends of Procontarinia matteiana Kieffer and Cecconi (Diptera: Cecidomyiidae). Pak J Zool 45:941-947

Mucina L, Rutherford M (2006) The vegetation of South Africa, Lesotho and Swaziland. South African National Biodiversity Institute, Pretoria

Nakagawa S, Schielzeth H (2013) A general and simple method for obtaining $R^{2}$ from generalized linear mixed-effects models. Methods Ecol Evol 4:133-142

O’Neill K, Skinner S (1990) Ovarian egg size and number in relation to female size in five species of parasitoid wasps. J Zool 220:115-122

Pacala S, Hassell M (1991) The persistence of host-parasitoid associations in patchy environments. II. Evaluation of field data. Am Nat 138:584-605

Protasov A, Blumberg D, Brand D, La Salle J, Mendel Z (2007) Biological control of the eucalyptus gall wasp Ophelimus maskelli (Ashmead): taxonomy and biology of the parasitoid species Closterocerus chamaeleon (Girault), with 
information on its establishment in Israel. Biol Control 42:196-206

Raman A, Burckhardt D, Harris K (2009) Biology and adaptive radiation in the gall-inducing Cecidomyiidae (Insecta Diptera) and Calophyidae (Insecta Hemiptera) on Mangifera indica (Anacardiaceae) in the Indian subcontinent. Trop Zool 22:27-56

Rosenheim J, Mangel M (1994) Patch-leaving rules for parasitoids with imperfect host discrimination. Ecol Entomol 19:374-380

Schooler S, Ives A, Harmon J (1996) Hyperparasitoid aggregation in response to variation in Aphidius ervi host density at three spatial scales. Ecol Entomol 21:249-258

Snyder W, Ives A (2001) Generalist predators disrupt biological control by a specialist parasitoid. Ecology 82:705-716

Snyder W, Ives A (2003) Interactions between specialist and generalist natural enemies: parasitoids, predators, and pea aphid biocontrol. Ecology 84:91-107

Taylor A (1993) Heterogeneity in host-parasitoid interactions: "aggregation of risk" and the " $\mathrm{CV}^{2}>1$ rule". Trends Ecol Evol 8:400-405

Thies C, Tscharntke T (1999) Landscape structure and biological control in agroecosystems. Science 285:893-895

Thies C, Haenke S, Scherber C, Bengtsson J, Bommarco R, Clement LW, Ceryngier P, Dennis C, Emmerson M, Gagic V, Hawro V, Liira J, Weisser WW, Winqvist C, Tscharntke $\mathrm{T}$ (2011) The relationship between agricultural intensification and biological control: experimental tests across Europe. Ecol Appl 21:2187-2196

Thomson L, Hoffmann A (2013) Spatial scale of benefits from adjacent woody vegetation on natural enemies within vineyards. Biol Control 64:57-65

Tylianakis J, Didham R, Wratten S (2004) Improved fitness of aphid parasitoids receiving resource subsidies. Ecology 85:658-666 van Veen FJF, Müller CB, Adriaanse ICT, Godfray HCJ (2002) Spatial heterogeneity in risk of secondary parasitism in a natural population of an aphid parasitoid. J Anim Ecol 71:463-469

Venables W, Ripley B (2002) Modern applied statistics with S, 4th edn. Springer, New York

Wagenmakers E, Farrell S (2004) AIC model selection using Akaike weights. Psychon Bull Rev 11:192-196

Wang X, Keller M (2002) A comparison of the host-searching efficiency of two larval parasitoids of Plutella xylostella. Ecol Entomol 27:105-114

Zuur AF, Ieno EN, Walker NJ, Saveliev AA, Smith GM (2009) Mixed effects models and extensions in ecology with R. Springer, New York

William H. Morgan carried out this research for the dissertation element of his MSc studies at the University of Exeter under supervision of Frank van Veen, whose research focuses primarily on the dynamics of interacting species.

Elisa Thébault is a theoretical ecologist researching the structure and dynamics of networks of interacting species.

Colleen L. Seymour research focuses on Ecosystem Services in biodiversity rich areas.

F. J. Frank van Veen Colleen Seymour, Elisa Thébault and Frank van Veen jointly lead an international research programme aimed at integrating fundamental empirical and theoretical ecology with expertise in applied ecology. This research was conducted as part of this programme. 